\title{
The importance of publishing laboratory observations- reply to Camus and Krimer
}

\author{
Andrew K. Davis • Kerry Holcomb
}

Received: 27 April 2009 / Accepted: 29 July 2009 /Published online: 18 August 2009

(C) Springer-Verlag London Limited 2009

Dear Editor,

In the February 2009 issue of this journal, Camus and Krimer (2009) commented on a manuscript we authored that described the appearance of inclusion bodies in a set of wild painted turtles in northeast Georgia, USA (Davis and Holcomb 2008). In our paper, we obtained detailed measurements of these structures and of the cells that contain them, as well as the level of occurrence within the set of captured turtles. We did not know the origin of these structures, though we presented what we thought was the most relevant literature review on the subject of intraerythrocytic inclusion bodies, which was biased toward infectious causes. Camus and Krimer (2009) took objection to this focus on infectious diseases and pointed out that these structures could also be degenerative organelles and provided a selected number of references to support this claim.

We appreciate the authors' interest in this project and can even accept their claim, but we feel compelled to point out that our rationale for including the infectious literature in our paper was driven largely by the limited number of published records on the subject, and of those that are published, nearly all focus on infectious causes. In our literature search for this project, we found little else but disease-related publications in printed or online sources. In fact, a search of the words "intraerythrocytic" and/or "inclusion bodies" in Pubmed, Web of Science, and even

A. K. Davis $(\bowtie) \cdot K$. Holcomb

D.B. Warnell School of Forestry and Natural Resources,

The University of Georgia,

Athens, GA 30602, USA

e-mail: akdavis@uga.edu
Google Scholar yields only references with a diseasebased focus. None of the papers listed by Camus and Krimer (2009) appear in such a search. We also point out that other investigators have found similar-appearing inclusions in reptiles and they too included infectious disease literature in their report (Eiras et al. 2000), reflecting the lack of literature to the contrary.

We can accept the possibility that these structures are degenerative organelles, though we might suggest that if indeed these inclusion bodies are routinely found in reptiles in their pathology lab, and since Drs. Camus and Krimer appear exceptionally knowledgeable about the subject, then these investigators would be ideally-suited to set the record straight by synthesizing the relevant literature, describing the prevalence of the structures in reptile species, cataloging their observations, and above all, publish their findings in peer-reviewed, accessible journals, so that the next investigator who observes these structures and performs a literature search would be steered in the right direction.

\section{References}

Camus MS, Krimer PM (2009) Comment on Davis and Holcomb: "Intraerythrocytic inclusion bodies in painted turtles (Chrysemys picta picta) with measurements of affected cells. Comp Clin Pathol 18:99. doi:10.1007/s00580-008-0792-5

Davis AK, Holcomb KL (2008) Intraerythrocytic inclusion bodies in painted turtles (Chrysemys picta picta) with measurements of affected cells. Comp Clin Pathol 17:51-54. doi:10.1007/s00580007-0705-Z

Eiras JC, Dellinger T, Davies AJ, Costa G, de Matos APA (2000) Intraerythrocytic inclusion bodies in the loggerhead sea turtle Caretta caretta from Madeira. J Mar Biol Assoc U K 80:957958. doi:10.1017/S0025315400003015 